\title{
Update on Epidemiology and Circulating Genotypes of Rotavirus in Iranian Children With Severe Diarrhea: 1986-2015
}

\author{
Somayeh Jalilvand ${ }^{1}$, Farzin Roohvand ${ }^{2}$, Arash Arashkia ${ }^{2}$, Zabihollah Shoja ${ }^{2 *}$ \\ ${ }^{1}$ Virology Department, School of Public Health, Tehran University of Medical Sciences, Tehran, Iran \\ ${ }^{2}$ Virology Department, Pasteur Institute of Iran, Tehran, Iran
}

Corresponding Author: Zabihollah Shoja, PhD, Assistant Professor, Virology Department, Pasteur Institute of Iran, Tehran, Iran. Tel: +98-2166496682, Fax: +98-2166496682, Email: zshoja@razi.tums.ac.ir

Received December 9, 2017; Accepted January 29, 2018; Online Published February 12, 2018

\begin{abstract}
Rotaviruses are the most common cause of severe diarrhea in children under 5 years of age worldwide with a higher prevalence in developing countries. In accordance with the World Health Organization (WHO) recommendations for the global use of rotavirus vaccines, it is important to review trends of rotavirus epidemiology, distribution and diversity of rotavirus strains in the pre-vaccine period. In Iran, the average rotavirus positivity rate is $40.04 \%$ in all patients under 5 years of age hospitalized for acute gastroenteritis (AGE). Studies have shown a substantial increase in the rotavirus detection rate over time from 1986 to 2013 . Moreover, there has been continued predominance of $\mathrm{G}(\mathrm{G} 1)$ and $\mathrm{P}(\mathrm{P}[8])$ genotypes, although the peak prevalence of $\mathrm{G} 1$ appeared to decline in 2007-2011 compared to 2001-2006. The data presented in this review, which suggests a change in the pattern of rotavirus genotypes in the Iranian population, further highlights the important role of continuous monitoring of rotavirus genotypes before starting any national rotavirus vaccination program.
\end{abstract}

Keywords: Rotavirus Group A, Epidemiology, Genotype, Iran

Citation: Jalilvand S, Roohvand F, Arashkia A, Shoja Z. Update on epidemiology and circulating genotypes of rotavirus in Iranian children with severe diarrhea: 1986-2015. Int J Travel Med Glob Health. 2018;6(1):7-10. doi:10.15171/ijtmgh.2018.02.

\section{Introduction}

Acute gastroenteritis (AGE), an important symptom of most enteric infections, is most frequent in children under 5 years of age. Several viruses are thought to cause AGE. These include rotaviruses, noroviruses, sapoviruses, enteric adenoviruses serotypes 40 and 41, astroviruses, human parechoviruses, aichiviruses and, picobirnaviruses, as well as the less frequent toroviruses and coronaviruses..$^{1-3}$ Rotaviruses, non-enveloped viruses of the Reoviridae family, are the leading cause of AGE in children under 5 years of age worldwide ${ }^{4,5}$ and are responsible for the deaths of approximately half a million children annually. ${ }^{6}$ In the pre-rotavirus vaccine era, more than $85 \%$ of all deaths were estimated to occur in the lowincome countries of Africa and Asia. ${ }^{7}$

Rotavirus vaccines have been identified as the best strategy to decreasing the burden of rotavirus-related AGE. Since 2006, 2 live attenuated rotavirus vaccines, RotaTeq (Merck, USA) and Rotarix (GSK Biologicals, Belgium) have been licensed ${ }^{8,9}$ and recommended to the global health community by the World Health Organization (WHO) Strategic Advisory
Group of Experts, particularly in countries with high diarrhearelated mortality in children under 5 years of age. ${ }^{10}$

The serological cross-reactivity of the middle protein VP6 allows differentiation of 8 rotavirus groups or species (rotavirus group A to $\mathrm{H}$ ), ${ }^{11,12}$ with group A being the major causative agent of AGE in children under 5 years of age worldwide. Based on the glycoprotein VP7 (G) and the protease-cleaved protein VP4 (P) types, rotaviruses have been classified into at least $27 \mathrm{G}$ and $35 \mathrm{P}$ genotypes. ${ }^{13}$ Moreover, a genotype classification system using the sequence of all 11 genomic RNA segments has been suggested for differentiating genotypes. ${ }^{13,14}$ Strain combinations G1P[8], G2P [4], G3P [8], $\mathrm{G} 4 \mathrm{P}[8]$ and G9P [8] have been shown to contribute to over $90 \%$ of rotavirus infections worldwide. Of these, the G1P[8] genotype is predominant in most regions. ${ }^{15,16}$

In 2012 and 2016, WHO provided reports on global estimation of childhood deaths due to rotavirus infection during 2008 and 2013, respectively. In Iran, about 2000 deaths in 2008 and 270 deaths in 2013 were estimated to be caused by the rotavirus. ${ }^{17,18}$ Accordingly, detection rates of over $40 \%$

Copyright $\odot 2018$ The Author(s). This is an open-access article distributed under the terms of the Creative Commons Attribution License (http:// creativecommons.org/licenses/by/4.0), which permits unrestricted use, distribution, and reproduction in any medium, provided the original work is properly cited. 
implies the importance and necessity of rotavirus vaccination programs to decrease the corresponding morbidity and mortality rates in Iran. Although rotavirus vaccine programs have not been launched in Iran to date, introduction of rotavirus vaccines into vaccination programs are considered to be a high priority by the Iranian Health Ministry. Moreover, several studies support the incorporation of a rotavirus vaccine into the Expanded Program on Immunization in Iranian children as highly cost-effective. ${ }^{19-21}$

Prior to implementing a rotavirus vaccine, it is important to provide precise information about rotavirus prevalence, genotype distribution and changing trends in circulating rotavirus genotypes. In this context, the present review was conducted to update the epidemiological data on the rotavirus and estimate the patterns and distribution of rotavirus genotypes among Iranian children under 5 years of age using studies and data published between 1986 and 2015. This report will be useful for recommending appropriate policies for rotavirus vaccination before beginning a national rotavirus vaccination program in Iran.

The review of works published from 1986 to 2015 was conducted to assess the epidemiology and rotavirus genotypes distribution in Iran. The data was obtained by searching Medline, PubMed and references from relevant articles using the terms "rotavirus" and "Iran" in combination with "strain", "genotype", "prevalence" and "children $<5$ years". The selected works were restricted to studies relevant to rotavirus prevalence and genotypes. Articles related to methodology, case reports, basic information and vaccines as well as duplicate data were excluded. The data obtained reports either on the prevalence of rotavirus infection in children under 5 years of age from 1986 to 2015 or on the distribution of rotavirus genotypes G and P from 2001 to 2011 or both. Data extraction was performed using Microsoft Office Excel database and includes the following data: first author; journal name; year of publication; sampling period; sample size; number and percentage of positive rotavirus cases; number and percentage of rotavirus genotypes G1, G2, G3, G4, G8, G9, G12, P[4], P[8], P[9], P[10] and untyped G or P. Studies presenting strain combinations $G[P]$ were separately categorized by G or P genotypes. Excel and GraphPad Prism (version 5) were used for statistical analysis.

\section{Prevalence of Rotavirus in Iran}

In accordance with WHO recommendations for the global use of rotavirus vaccines, it is important to review trends of rotavirus epidemiology and distribution and the diversity of rotavirus strains in the pre-vaccine period. WHO estimates that the number of rotavirus deaths in children under 5 years of age in Iran declined from 2000 deaths in 2008 to 270 deaths in 2013. Despite the estimated decline, the study estimated that rotavirus in Iranian children under 5 years of age caused $40.04 \%$ (95\% CI; 33.89\%-46.18\%; $\mathrm{N}=4227$ ) of all hospitalizations for severe gastroenteritis. This is similar to estimates of rotavirus infection prevalence published in epidemiologic studies for the Eastern Mediterranean region. In this region, the estimated proportion of rotavirus-related AGE was $25 \%(\mathrm{~N}=228)$ in $1986-1990,18 \%(\mathrm{~N}=158)$ in 1990 -
1995 , no data in $1995-2000,27.33 \%(\mathrm{~N}=775)$ in $2000-2005$, $44.47 \%$ (2918) in $2005-2010$ and $42.77 \%(\mathrm{~N}=148)$ in 2010 2015 (Figure 1).

These results indicate an increase in the rotavirus detection rate over time from 1986 to 2013. This may reflect real regional and temporal differences and study populations from different time periods, but may also be largely related to general improvements in the methods of rotavirus detection. Moreover, the prevalence of rotavirus infection for hospitalized gastroenteritis was higher than the prevalence in outpatient departments. ${ }^{22}$ This suggests that the notion that the rotavirus rate is currently increasing should be challenged and needs further investigation.

\section{Distribution of Rotavirus Genotypes in Iran}

During the 1990s and 2000s, novel strains (G9P [8], G9P[6], $\mathrm{G} 12 \mathrm{P}[8]$ and $\mathrm{G} 12 \mathrm{P}[6])$ as well as major strains (G1P[8], $\mathrm{G} 2 \mathrm{P}[4]$, G3P[8] and G4P[8] first detected during the 1980 s) $)^{23,24}$ have emerged to become medically important strains worldwide. Moreover, the G5P[8] and G8P[6] strains are considered to be important local strains. ${ }^{24}$ In Iran, data on the $G$ genotype from 886 positive rotavirus cases from 2001 to 2011 show that the most prevalent G genotype was G1 at $45.48 \%(\mathrm{~N}=403)$, followed by $\mathrm{G} 4$ at $14.78 \%(\mathrm{~N}=131), \mathrm{G} 2$ at $8.46 \%(\mathrm{~N}=75), \mathrm{G} 8$ at $5.98 \%(\mathrm{~N}=53), \mathrm{G} 9$ at $2.82 \%(\mathrm{~N}=25)$, $\mathrm{G} 3$ at $1.58 \%(\mathrm{~N}=14), \mathrm{G} 12$ at $0.2 \%(\mathrm{~N}=1)$ and nontypeable $\mathrm{G}$ at $20.76 \%(\mathrm{~N}=184)$ (Figure $2 \mathrm{~A})$.

G genotype analysis based on the study periods of 20012006 and 2007-2011 was also performed to determine the trends of rotavirus $\mathrm{G}$ genotype distribution in Iran (Figure $3 \mathrm{~A})$. These results indicate continued predominance of the G1 genotypes with emergence of G8, G9 (2001-2006 to 20072011), G12 (2001-2006) and novel genotypes. However, the relative frequency of the G1 genotype appeared to decrease during 2 time periods (2001-2006 and 2007-2011). Moreover, data analysis also showed an increase in the prevalence of the
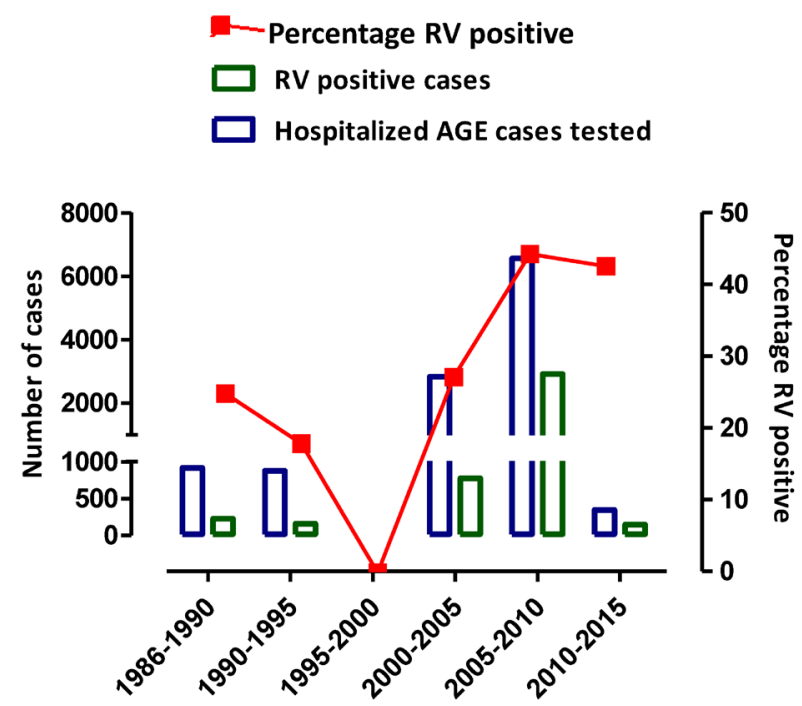

Figure 1. Number of Hospitalized AGE Cases (Blue Bars) and Hospitalized AGE Cases Testing Rotavirus-Positive (Green Bars) From 1986 to 2015. The red line indicates the percentage of rotavirus-positive cases. 


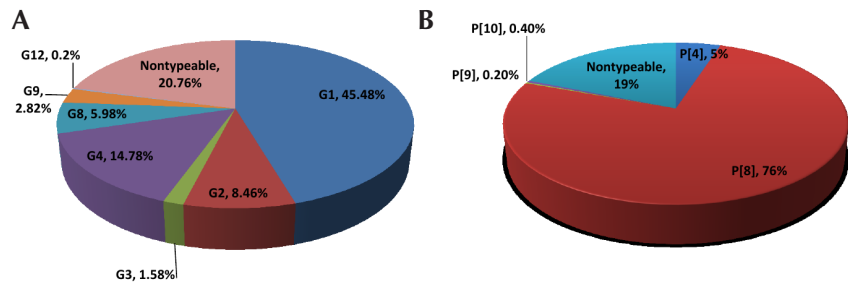

Figure 2. Distribution of Rotavirus Genotypes in Iran: (A) G Genotypes From 2001 to 2011; (B) P Genotypes From 2001 to 2008.
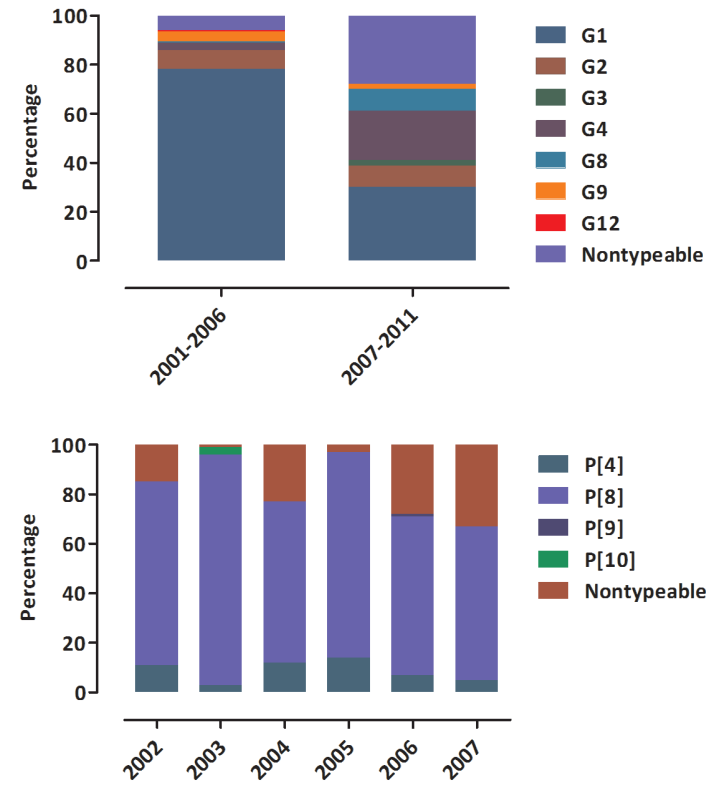

Figure 3. Prevalence of Rotavirus in Iran: (A) G Genotypes in 2001-2006 and 2007-2011; (B) P Genotypes in 2001-2002, 2003-2004, 2004-2005, 2005-2006, 2006-2007 and 2007-2008.

G4 and G8 genotypes in 2001-2006 and 2007-2011 in Iran. Although G1 has been prevalent in past years, genotype G4 and novel genotypes may be able to (re)emerge as dominant genotypes in the future.

Data on the $\mathrm{P}$ genotype of 445 positive rotavirus cases from 2002 to 2007 indicate that the most prevalent $\mathrm{P}$ genotype was $\mathrm{P}[8]$ at $76 \%(\mathrm{~N}=336)$, followed by $\mathrm{P}[4]$ at $5 \%(\mathrm{~N}=22)$, $\mathrm{P}[10]$ at $0.4 \%(\mathrm{~N}=2)$, at $\mathrm{P}[9], 0.1 \%(\mathrm{~N}=1)$ and nontypeable $\mathrm{P}$ at $19 \%(\mathrm{~N}=84)$ (Figure $2 \mathrm{~B})$. $\mathrm{P}$ genotype analysis for the study period of 2002 to 2007 showed patterns similar to all study periods. Among the P genotypes, although P[8] was frequently detected and showed patterns similar to all study periods, the $\mathrm{P}[4]$ genotype was most common and the $\mathrm{P}[9]$ $(\mathrm{N}=1)$ and $\mathrm{P}[10](\mathrm{N}=2)$ genotypes were rarely found in Iran (Figure 3B).

The rotavirus genotyping data presented in this study could help to identify the prevalent genotypes in past years. In Iran, $\mathrm{G} 1 \mathrm{P}[8], \mathrm{G} 2 \mathrm{P}[4]$ and $\mathrm{G} 4 \mathrm{P}[8]$ accounted for over $60 \%$ of all detected rotavirus strains, with $\mathrm{G} 1 \mathrm{P}[8]$ alone representing $50 \%$ of all rotavirus infections. ${ }^{22}$ Emerging and uncommon genotypes (G9P[8], G3P[8], G1P[4], G3P[9], G12P[8], $\mathrm{G} 1 \mathrm{P}[10]$ and G8P[NT]), were also found, suggesting a diversity of rotavirus genotypes in Iranian children. Several studies have reported uncommon combinations, G2P[8], $\mathrm{G} 1 \mathrm{P}[4]$ and $\mathrm{G} 4 \mathrm{P}[4]$, originating through reassortment between common genotypes.

Animals may have been reservoirs for the generation of reassortant rotaviruses among animal species. In agreement with prior studies, the G8 and $\mathrm{P}[9]$ genotypes of rotavirus have been found in animals in Iran, perhaps from the introduction of animal rotavirus strains into the human population, followed by reassortment. ${ }^{22}$ The results of our study indicate that the rate of nontyped strains has increased over time, which appears to be attributable to nucleotide mismatches in the primer binding or to newly emerging rotavirus genotypes. ${ }^{16}$

\section{Conclusion}

The two licensed rotavirus vaccines (Rotarix and RotaTeq) have not been introduced into vaccination programs in Iran to date. Before rotavirus vaccination, it is very important to obtain rotavirus molecular epidemiologic data and to monitor trends in the circulating rotavirus genotypes in Iran. Accordingly, the data presented in this review, which may indicate changes in the pattern of rotavirus genotypes in the Iranian population, further highlight the important role of continuous monitoring of rotavirus genotypes before starting any national rotavirus vaccination program. Future studies that include larger sample sizes from different regions of Iran are urgently needed.

\section{Authors' Contributions}

All authors significantly contributed towards this study.

\section{Conflict of Interest Disclosures}

The authors declare no conflicting financial or other interests.

\section{Ethical Approval}

Not applicable.

\section{Funding/Support}

This study has been funded and supported by Pasteur Institute of Iran (grant No. 881).

\section{References}

1. Xu C, Fu J, Zhu Y. A Narrative Review of Norovirus Gastroenteritis: More Global Attention Is Needed. Int J Travel Medicine Glob Health. 2016;4(4):101-106. doi:10.21859/ijtmgh-040402.

2. Jalilvand S, Marashi SM, Tafakhori A, Shoja Z. Extraintestinal Involvement of Rotavirus Infection in Children. Arch Iran Med. 2015;18(9):604-605. doi:0151809/aim.0010.

3. Tan EM, Cawcutt KA, Zomok CD, Go RS, Sia IG. Activity of Nitazoxanide Against Viral Gastroenteritis: A Systematic Review. Int J Travel Medicine Glob Health. 2017;5(4):107-112. doi:10.15171/ ijtmgh.2017.22.

4. Bishop RF, Davidson GP, Holmes IH, Ruck BJ. Virus particles in epithelial cells of duodenal mucosa from children with acute non-bacterial gastroenteritis. Lancet. 1973;2(7841):1281-1283. doi:10.1016/S0140-6736(73)92867-5.

5. Bishop RF, Davidson GP, Holmes IH, Ruck BJ. Detection of a new virus by electron microscopy of faecal extracts from children with acute gastroenteritis. Lancet. 1974;1(7849):149-151. doi:10.1016/ 
S0140-6736(74)92440-4.

6. Tate JE, Burton AH, Boschi-Pinto C, Steele AD, Duque J, Parashar UD. 2008 estimate of worldwide rotavirus-associated mortality in children younger than 5 years before the introduction of universal rotavirus vaccination programmes: a systematic review and metaanalysis. Lancet Infect Dis. 2012;12(2):136-141. doi:10.1016/ s1473-3099(11)70253-5.

7. Rotavirus surveillance--worldwide, 2001-2008. MMWR Morb Mortal Wkly Rep. 2008;57(46):1255-1257.

8. Ruiz-Palacios GM, Perez-Schael I, Velazquez FR, et al. Safety and efficacy of an attenuated vaccine against severe rotavirus gastroenteritis. N Engl J Med. 2006;354(1):11-22. doi:10.1056/ NEJMoa052434.

9. Vesikari T, Matson DO, Dennehy P, et al. Safety and efficacy of a pentavalent human-bovine (WC3) reassortant rotavirus vaccine. N Engl J Med. 2006;354(1):23-33. doi:10.1056/NEJMoa052664.

10. Meeting of the immunization Strategic Advisory Group of Experts, April 2009--conclusions and recommendations. Wkly Epidemiol Rec. 2009;84(23):220-236.

11. Matthijnssens J, Otto PH, Ciarlet M, Desselberger U, Van Ranst M, Johne R. VP6-sequence-based cutoff values as a criterion for rotavirus species demarcation. Arch Virol. 2012;157(6):1177-1182. doi:10.1007/s00705-012-1273-3.

12. Tang B, Gilbert JM, Matsui SM, Greenberg HB. Comparison of the rotavirus gene 6 from different species by sequence analysis and localization of subgroup-specific epitopes using sitedirected mutagenesis. Virology. 1997;237(1):89-96. doi:10.1006/ viro.1997.8762.

13. Matthijnssens J, Ciarlet M, Heiman E, et al. Full genome-based classification of rotaviruses reveals a common origin between human Wa-Like and porcine rotavirus strains and human DS-1like and bovine rotavirus strains. J Virol. 2008;82(7):3204-3219. doi:10.1128/jvi.02257-07.

14. Matthijnssens J, Ciarlet M, Rahman M, et al. Recommendations for the classification of group A rotaviruses using all 11 genomic RNA segments. Arch Virol. 2008;153(8):1621-1629. doi:10.1007/ s00705-008-0155-1.
15. Banyai K, Laszlo B, Duque J, et al. Systematic review of regional and temporal trends in global rotavirus strain diversity in the pre rotavirus vaccine era: insights for understanding the impact of rotavirus vaccination programs. Vaccine. 2012;30 Suppl 1:A122130. doi:10.1016/j.vaccine.2011.09.111.

16. Santos N, Hoshino Y. Global distribution of rotavirus serotypes/ genotypes and its implication for the development and implementation of an effective rotavirus vaccine. Rev Med Virol. 2005;15(1):29-56. doi:10.1002/rmv.448.

17. WHO. Global Rotavirus Information and Surveillance Bulletin. http://www.who.int/immunization/diseases/rotavirus/rota_info_ surv_bulletin/en/. Published 2012.

18. WHO. Child cause of death: estimates 2000-2013. http://www.who. int/healthinfo/global_burden_disease/estimates_child_cod_2013/ en/. Published 2015.

19. Mousavi Jarrahi Y, Zahraei SM, Sadigh N, et al. The cost effectiveness of rotavirus vaccination in Iran. Hum Vaccin Immunother. 2016;12(3):794-800. doi:10.1080/21645515.2015.1087626.

20. Javanbakht M, Moradi-Lakeh M, Yaghoubi M, et al. Cost-effectiveness analysis of the introduction of rotavirus vaccine in Iran. Vaccine. 2015;33 Suppl 1:A192-200. doi:10.1016/j.vaccine.2014.12.035.

21. Shakerian S, Moradi Lakeh M, Esteghamati A, Zahraei M, Yaghoubi M. Cost-Effectiveness of Rotavirus Vaccination for Under-Five Children in Iran. Iran J Pediatr. 2015;25(4):e2766. doi:10.5812/ ijp. 2766.

22. Shoja Z, Jalilvand S, Mokhtari-Azad T, Nategh R. Epidemiology of cocirculating human rotaviruses in Iran. Pediatr Infect Dis J. 2013;32(4):e178-181. doi:10.1097/INF.0b013e31827ee392.

23. Matthijnssens J, Heylen E, Zeller M, Rahman M, Lemey P, Van Ranst M. Phylodynamic analyses of rotavirus genotypes G9 and G12 underscore their potential for swift global spread. Mol Biol Evol. 2010;27(10):2431-2436. doi:10.1093/molbev/msq137.

24. Doro R, Laszlo B, Martella V, et al. Review of global rotavirus strain prevalence data from six years post vaccine licensure surveillance: is there evidence of strain selection from vaccine pressure? Infect Genet Evol. 2014;28:446-461. doi:10.1016/j.meegid.2014.08.017. 